\begin{tabular}{|c|c|c|}
\hline & $\begin{array}{c}\text { JURNAL } \\
\text { PENELITIAN PENDIDIKAN IPA }\end{array}$ & $\begin{array}{l}\text { e-ISSN : } 2407-795 X \\
\text { p-ISSN : 2460-2582 }\end{array}$ \\
\hline $\mathbb{N}^{1 P P}$ & http://jurnal.unram.ac.id/index.php/jpp-ipa & $\begin{array}{l}\text { Vol 2, No, } 1 \\
\text { Januari } 2016\end{array}$ \\
\hline
\end{tabular}

\title{
SINTESIS BARIUM M-HEKSAFERIT DENGAN DOPING LOGAM Zn MENGGUNAKAN METODE KOPRESIPITASI
}

\author{
Ilham Halik ${ }^{1}$, Aris Doyan ${ }^{2}$, Aliefman Hakim ${ }^{3}$ \\ Program Studi Magister Pendidikan IPA Program Pascasarjana Universitas Mataram ${ }^{123}$ \\ ilham8halik@gmail.com, arisdoyan@yahoo.co.id, aliefmanhakim27@gmail.com
}

\begin{abstract}
Key Words
Barium M-

Hexaferrites, synthesis, coprecipitasi

Abstract

The aims of this study to synthesis barium M-heksaferit doped metal Zn. Synthesis of BaM using coprecipitation method by varying the concentrate of dopan 0,0;0,3;0,6; dan 0,9 and varying the calcinations temperature 80, 400, 600 dan $800{ }^{\circ} \mathrm{C}$. The basic material used of Barium Carbonat $\left(\mathrm{BaCO}_{3}\right)$, Iron (III) Cloride Hexahydrate $\left(\mathrm{FeCl}_{3} .6 \mathrm{H}_{2} \mathrm{O}\right) \mathrm{ZnCl}_{2}$ dan $\mathrm{NH}_{4} \mathrm{OH}$. Synthesis process conducted at the Faculty of Mathematics and Natural Sciences Analytical Laboratories Unram. The final product of synthesis is varied colored powder light brown to dark depending on the dopan concentrate and calcinations temperature. It is found that the dark of sample increase with increase in dopan concentrate and the dark of sample increase with increase in calcinations temperature too, it is showed the product BaM can be used to softmagnetic
\end{abstract}

\begin{tabular}{lll}
\hline Kata Kunci & & Abstrak \\
\cline { 1 - 2 } Barium M- & & Penelitian ini bertujuan untuk mensintesis barium M-heksaferit yang didoping logam $\mathrm{Zn}$. \\
Heksaferit, & & Proses sintesis $\mathrm{BaM}$ menggunakan metode kopresipitasi dengan memvariasikan \\
sintesis, & & konsentrasi dopannya 0,$0 ; 0,3 ; 0,6 ;$ dan 0,9 serta memvariasikan temperatur kalsinasi 80, \\
kopresipitasi & & 400,600 dan $800{ }^{\circ} \mathrm{C}$. Bahan dasar yang digunakan adalah Barium Carbonat $\left(\mathrm{BaCO}_{3}\right)$ \\
& Iron (III) Cloride Hexahydrate $\left(\mathrm{FeCl}_{3} .6 \mathrm{H}_{2} \mathrm{O}\right) \mathrm{ZnCl}_{2}$ dan $\mathrm{NH}_{4} \mathrm{OH}$. Proses sintesis \\
& dilakukan di laboratorium Analitik Fakultas MIPA Unram. Hasil akhir sintesis berupa \\
& serbuk BaM berwarna bervariasi coklat muda hingga coklat tua bergantung konsentrasi \\
& dopan dan temperatur kalsinasi. Semakin tinggi konsentrasi dopan maka warna serbuk \\
& sampel semakin gelap dan semakin tinggi temperatur kalsinasi maka warna serbuk \\
& sampel semakin gelap pula yang mengindikasikan BaM dapat digunakan sebagai bahan \\
& softmagnetic.
\end{tabular}




\section{PENDAHULUAN}

Penelitian di bidang material magnetik sangat intensif dilakukan pada akhir dekade ini. Hal tersebut dikarenakan penerapan material magnetik mampu melingkupi berbagai aspek yang terkait dengan teknologi maju dewasa ini. Salah satu material magnetik yang banyak dikembangkan adalah bahan magnetik barium M-heksaferit (BaM). Sifat kemagnetan dari BaM mudah untuk dilakukan rekayasa dalam hal sifat kemagnetannya melalui mekanisme subtitusi ion-ion metal, sehingga mampu menjangkau range kemagnetan dari sifat kemagnetan paling lemah sampai sifat kemagnetan yang paling kuat. Dengan sifat yang demikian, bahan tersebut dapat diaplikasikan ke media perekaman, interferensi elektromagnetik, magnetik cairan, perangkat microwave, dan sebagainya (Sholihah, 2012).

Pada penelitian ini proses sintesis menggunakan mekanisme substitusi ion-ion yaitu $\mathrm{Zn}$ dengan metode kopresipitasi. Penambahan ion dopan $\mathrm{Zn}$ diharapkan dapat mereduksi sifat magnetik dari barium M-heksaferit $\quad \mathrm{BaFe}_{12-\mathrm{x}} \mathrm{Zn}_{\mathrm{x}} \mathrm{O}_{19}, \quad$ sebagai akibat dari terganggunya arah momen magnet dengan munculnya ion substitusional hingga domainnya menjadi random (Ramli, 2012). Selain itu, kenaikan sifat magnet $\mathrm{BaFe}_{12} \mathrm{O}_{19}$ terkait dengan ukuran butir yang semakin kecil (skala nano) (Hasanah, 2012).

Akhir - akhir ini, $\mathrm{BaFe}_{12} \mathrm{O}_{19}$ dihasilkan melalui proses kristalisasi dengan menggunakan metode matrik kaca, metode hidrotermal, metode salt melting, metode sol - gel, dan kopresipitasi. Tetapi tak satupun dari metode tersebut mampu menghasilkan BaM pada temperatur ruang. Meskipun demikian pada sintesis tersebut BaM menggunakan metode kopresipitasi dapat dihasilkan pada temperatur yang lebih rendah (sekitar 700-900 ${ }^{\circ} \mathrm{C}$ ) jika dibandingkan dengan metode reaksi larutan padat temperatur kalsinasi $\geq 1000{ }^{\circ} \mathrm{C}$ (Darminto, 2011).

Pada penelitian sebelumnya telah dilakukan sintesis BaM dengan berbagai metode, dopan dan temperatur kalsinasi seperti mechanical alloying pada temperatur kalsinasi $900{ }^{\circ} \mathrm{C}$ (Fadzidah, 2014), metode sol gel dengan dopan $\mathrm{Mg}$ pada temperatur kalsinasi $650-950 \quad{ }^{\circ} \mathrm{C}$ (Chauhan, 2012), metode kopresipitasi dengan dopan $\mathrm{Zn}$ pada temperatur kalsinasi $150{ }^{\circ} \mathrm{C}$ (Ramli, 2012)

Berdasarkan uraian diatas, maka pada penelitian ini dilakukan sintesis barium M-heksaferit menggunakan metode kopresipitasi dan didoping $\mathrm{Zn}$ dengan konsentrasi berbeda-beda yaitu 0,$0 ; 0,3$; 0,$6 ; \quad 0,9$ serta temperatur kalsinasi (pemanasan) yang divariasikan pula, 80, 400, 600 dan $800{ }^{\circ} \mathrm{C}$. Metode kopresipitasi 
pada penelitian ini adalah metode yang mudah untuk menghasilkan prekursor heksaferit (Sudati, 2012). Pemilihan variasi konsentrasi dan variasi temperatur kalsinasi berdasarkan hasil penelitian-penelitian sebelumnya sehingga diharapkan pada penelitian ini mendapatkan hasil yang lebih baik dari penelitian sebelumnya. BaM mulai terbentuk pada temperatur kalsinasi $500^{\circ} \mathrm{C}$ meskipun berupa fase amorf. Fase tersebut akan berkurang dan menjadi kristalin sempurna seiring bertambahnya temperatur kalsinasi, yakni sekitar 700$900^{\circ} \mathrm{C}$ (Darminto, 2011).

Barium M-heksaferit dengan struktur heksagonal dan seluruh turunannya memiliki sifat magnet yang spesifik sehingga dapat dimanfaatkan sebagai magnet permanen, media peredam magnetik dan peralatan aplikasi gelombang mikro lainnya (Af'idah, 2011). Barium Mheksaferit sebagai magnet ferit, disamping memiliki permeabilitas, permitivitas dan magnetisasi spontan yang relatif tinggi, juga tersusun oleh komponen-komponen oksida sehingga juga memiliki resistivitas listrik yang tinggi atau isolator yang baik (Sulistyo, 2012). Berdasarkan rumus kimia dan struktur kristalnya, heksaferit dikelompokkan menjadi 5 tipe, yaitu : tipe$\mathrm{M}\left(\mathrm{BaFe}_{12} \mathrm{O}_{19}\right)$, tipe-W $\left(\mathrm{BaMe}_{2} \mathrm{Fe}_{16} \mathrm{O}_{27}\right)$, tipe-X $\left(\begin{array}{llll}\mathrm{Ba}_{2} & \mathrm{Me}_{2} & \mathrm{Fe}_{28} & \mathrm{O}_{46}\end{array}\right)$, tipe-Y $\left(\mathrm{Ba}_{2} \mathrm{Me}_{2} \mathrm{Fe}_{12} \mathrm{O}_{22}\right)$ dan tipe-Z $\left(\mathrm{Ba}_{2} \mathrm{Me}_{2} \mathrm{Fe}_{24} \mathrm{O}_{41}\right)$ (Darminto, 2011).
Barium M-heksaferit atau dikenal dengan sebutan $\mathrm{BaM}$ memiliki rumus kimia $\mathrm{BaO} .6 \mathrm{Fe}_{2} \mathrm{O}_{3} \quad\left(\mathrm{BaFe}_{12} \mathrm{O}_{19}\right)$ dan struktur heksagonal yang sesuai dengan space group P 63/mmc. Sel komplek BaM tersusun atas 2 sistem kristal yaitu struktur kubus-pusat-sisi (face-centered-cubic) dan heksagonal mampat (hexagonal-closepacked) (Af'idah, 2011). Material yang memiliki sifat ferromagnetik bukan merupakan senyawa, tetapi berupa unsur murni. Biasanya dimiliki oleh logam transisi seperti $\mathrm{Fe}, \mathrm{Co}$, Ni dan beberapa logam tanah jarang seperti $\mathrm{Nd}$ dan Sm. Ferrimagnetik merupakan senyawa, dimana momen magnetiknya berasal dari atomatom ataupun ion-ion yang tidak saling menghilangkan secara sempurna (Saidah, 2012).

Salah satu metode sintesis yang sering digunakan adalah kopresipitasi. Metode kopresipitasi (pengendapan) adalah salah satu jenis teknik fabrikasi dengan cara kimia, teknik ini digunakan untuk memisahkan analit dari pengganggupengganggunya

\section{METODE PENELITIAN}

Sintesis BaM dilakukan dengan metode kopresipitasi. Bahan dasar yang digunakan dalam penelitian ini adalah $\mathrm{BaCO}_{3}, \mathrm{FeCl}_{3} \cdot 6 \mathrm{H}_{2} \mathrm{O}$, dan $\mathrm{ZnCl}_{2}$ sebagai dopan yang berguna untuk menurunkan sifat kemagnetannya dan dapat digunakan 
sebagai bahan softmagnetic. Semua bahan tersebut dalam bentuk serbuk dengan kemurnian 99,99\%. Sintesis BaM yang dilakukan dengan menggunakan variasi konsentrasi dopan $\mathrm{x}=0,0 ; 0,3 ; 0,6$; dan 0,9 dan memvariasikan temperatur kalsinasi 80 ${ }^{\circ} \mathrm{C}, 400{ }^{\circ} \mathrm{C}, 600{ }^{\circ} \mathrm{C}$ dan $800{ }^{\circ} \mathrm{C}$.

Proses sintesis dilakukan dengan mempersiapakan bahan yang akan digunakan dalam sintesis barium $\mathrm{M}$ heksaferit dengan menimbang masingmasing bahan sesuai kebutuhan. Selanjutnya melarutkan serbuk $\left(\mathrm{FeCl}_{3} \cdot 6 \mathrm{H}_{2} \mathrm{O}\right)$ dalam $\mathrm{H}_{2} \mathrm{O}$ dan diaduk menggunakan magnetic stierrer selama 30 menit (larutan 1) kemudian melarutkan serbuk $\mathrm{BaCO}_{3}$ dalam $\mathrm{HCl}$ menggunakan Hot plate magnetic stirrer pada temperatur
$70{ }^{\circ} \mathrm{C}$ (larutan 2) selanjutnya melarutkan serbuk $\mathrm{ZnCl}_{2}$ dalam $\mathrm{H}_{2} \mathrm{O}$ (larutan 3). Semua larutan tersebut, larutan 1, 2, 3 dicampurkan sambil diaduk selama 30 menit hingga homogen (larutan 4). Agar larutan 4 mengendap maka selanjutnya dilakukan titrasi $\mathrm{NH}_{4} \mathrm{OH}$ pada larutan 4 sampai terjadi pengendapan. Setelah itu larutan 4 dicuci dengan aquades sampai $\mathrm{pH}$ netral. Perkursor dikeringkan dengan temperatur $80{ }^{\circ} \mathrm{C}$ selama 4 jam dan digerus hingga berbentuk serbuk dan benar-benar lembut. Selanjutnya prekursor dikalsinasi pada temperatur $80,400,600$ dan $800{ }^{\circ} \mathrm{C}$ selama empat jam.

Proses sintesis secara sistematis dapat dilihat pada gambar 1 berikut

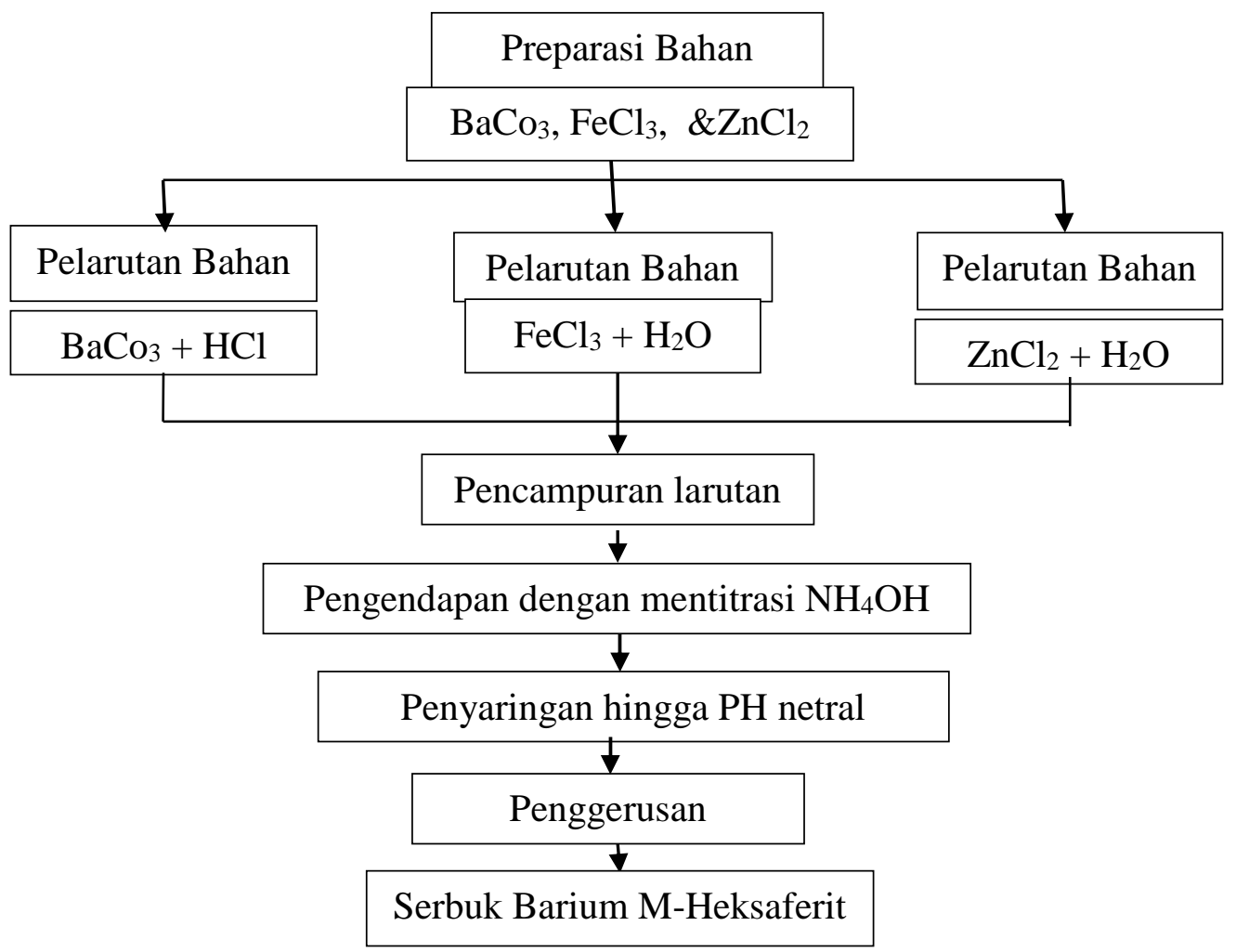

Gambar 1 Diagram alir preparasi dan pengujian sampel barium M-heksaferit dengan dopan Zn (Sumber: Halik, 2015) 
Proses pembuatan sampel mengikuti (Susilawati, 2013), yang berbeda adalah jenis dan konsentrasi doping serta temperatur kalsinasi. Hasil proses sintesis ini selanjutnya akan dikarakterisasi dan diuji sifat kemagnetan dan kelistrikannya pada tahap berikutnya.

\section{HASIL DAN PEMBAHASAN}

Pada penelitian ini telah dilakukan sintesis barium M-heksaferit yang didoping Zn menggunakan metode kopresipitasi dengan memvariasikan konsentrasi dopan 0,$0 ; 0,3 ; 0,6 ;$ dan 0,9 serta memvariasikan temperatur kalsinasi 80, 400, 600 dan 800 ${ }^{\circ} \mathrm{C}$. dalam melakukan sintesis barium Mheksaferit, komposisi masing-masing unsur penyusunnya dihitung menggunakan persamaan reaksi kimia sebagai berikut.

$$
\begin{aligned}
& \begin{array}{l}
11,7 \mathrm{FeCl}_{3} \cdot 6 \mathrm{H}_{2} \mathrm{O}+11,7 \mathrm{H}_{2} \mathrm{O} \longrightarrow \mathrm{BaCl}_{2}+\mathrm{H}_{2} \mathrm{CO}_{3} \\
\mathrm{BaCO}_{3}+2 \mathrm{HCl} \longrightarrow \mathrm{BaCl}_{3}+81,9 \mathrm{H}_{2} \mathrm{O}
\end{array} \\
& \begin{array}{r}
0.3 \mathrm{ZnCl}_{2}+0,3 \mathrm{H}_{2} \mathrm{O} \longrightarrow \mathrm{OZnCl}+0,3 \mathrm{H}_{2} \mathrm{O} \\
11,7 \mathrm{FeCl}_{3}+\mathrm{BaCl}_{2}+\mathrm{H}_{2} \mathrm{CO}_{3}+0,3 \mathrm{ZnCl}_{2}+82,2 \mathrm{H}_{2} \mathrm{O}+37,7 \mathrm{NH}_{4} \mathrm{OH}
\end{array} \\
& \longrightarrow \mathrm{BaFe}_{11,7} \mathrm{Zn}_{0,3} \mathrm{O}_{19}+37,7 \mathrm{NH}_{4} \mathrm{Cl}+101,9 \mathrm{H}_{2} \mathrm{O}+\mathrm{CO}_{2}
\end{aligned}
$$

Berdasarkan persamaan diatas maka dalam proses sintesis dapat ditentukan komposisi unsur/senyawa yang digunakan seperti pada tabel 1 berikut.

Tabel 1 komposisi masing-masing unsur penyusun $\mathrm{BaFe}_{12-\mathrm{x}} \mathrm{Zn}_{\mathrm{x}} \mathrm{O}_{19}$

\begin{tabular}{ccccc}
\hline Nilai $x$ & \multicolumn{3}{c}{ Unsur/senyawa (gram) } & \multirow{2}{*}{ Senyawa yang terbentuk } \\
\cline { 2 - 4 } & $\mathrm{FeCl}_{3.6 \mathrm{H}_{2} \mathrm{O}}$ & $\mathrm{BaCO}_{3}$ & $\mathrm{Zn}$ & \\
\hline 0,3 & 28,3630 & 1,76950 & 0,36659 & $\mathrm{BaFe}_{11,7} \mathrm{Zn}_{0,3} \mathrm{O}_{19}$ \\
0,6 & 27,6328 & 1,76639 & 0,73182 & $\mathrm{BaFe}_{11,4} \mathrm{Zn}_{0,6} \mathrm{O}_{19}$ \\
0,9 & 26,4526 & 1,76325 & 1,10264 & $\mathrm{BaFe}_{11,1} \mathrm{Zn}_{0,9} \mathrm{O}_{19}$ \\
\hline
\end{tabular}

Hasil sintesis berupa serbuk barium M-heksaferit dengan warna bervariasi coklat muda hingga coklat tua tergantung pada konsentarsi dopan dan temperatur kalsinasi.

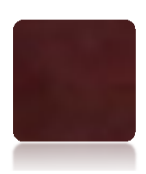

a

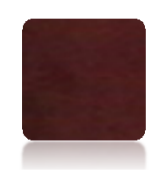

b

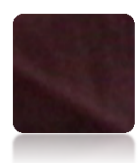

c

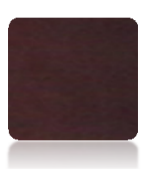

d
Gambar 2: Perubahan warna sampel $\mathrm{BaFe}_{12-\mathrm{x}} \mathrm{Zn}_{\mathrm{x}} \mathrm{O}_{19}$ berdasarkan perubahan konsentrasi dopan. (a) 0,0; (b) 0,3; (c) 0,6; (d) 0,9 (Sumber : Halik, 2015)
Berdasarkan gambar 2 dapat diketahui bahwa sampel barium $\mathrm{M}$ heksaferit tanpa dopan berwarna coklat muda atau berwarna paling cerah. Sedangkan pada konsentrasi dopan 0,9 sampel berwarna paling gelap atau coklat tua. Hal ini menandakan bahwa konsentrasi

dopan sangat mempengaruhi hasil sintesis ditinjau dari warna serbuk sampel. Semakin tinggi konsentarsi dopan maka 
warna sampel yang dihasilkan semakin gelap.

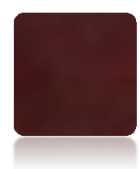

a

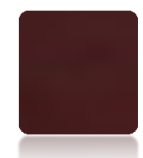

$\mathrm{b}$

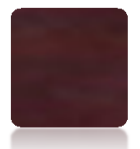

c

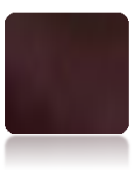

d
Gambar 3: Perubahan warna sampel

$\mathrm{BaFe}_{12} \mathrm{O}_{19}$ berdasarkan perubahan temperatur kalsinasi. (a) $80^{\circ} \mathrm{C}$; (b) 400 ${ }^{\circ} \mathrm{C}$; (c) $600{ }^{\circ} \mathrm{C}$; (d) $800{ }^{\circ} \mathrm{C}$ (Sumber: Halik, 2015)

Berdasarkan gambar 3 dapat diketahui bahwa sampel barium Mheksaferit dengan temperatur kalsinasi 80 ${ }^{\circ} \mathrm{C}$ berwarna coklat muda atau berwarna paling cerah. Sedangkan pada temperatur kalsinasi $800{ }^{\circ} \mathrm{C}$ sampel berwarna paling gelap atau coklat tua. Hal ini menandakan bahwa temperatur kalsinasi sangat mempengaruhi hasil sintesis ditinjau dari warna serbuk sampel. Semakin tinggi temperatur kalsinasi maka warna sampel yang dihasilkan semakin gelap.

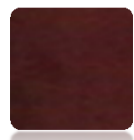

A

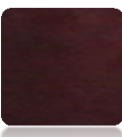

b

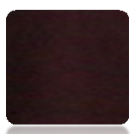

C

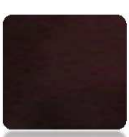

d
Gambar 4: Perubahan warna sampel $\mathrm{BaFe}_{11,7} \mathrm{Zn}_{0,3} \mathrm{O}_{19}$ berdasarkan perubahan temperatur kalsinasi. (a) $80{ }^{\circ} \mathrm{C}$; (b) 400 ${ }^{\circ} \mathrm{C}$; (c) $600{ }^{\circ} \mathrm{C}$; (d) $800{ }^{\circ} \mathrm{C}$ (Sumber: Halik, 2015)

Berdasarkan gambar 4 dapat diketahui bahwa sampel barium Mheksaferit dengan temperatur kalsinasi 80 ${ }^{\circ} \mathrm{C}$ berwarna coklat muda atau berwarna paling cerah. Sedangkan pada temperatur kalsinasi $800{ }^{\circ} \mathrm{C}$ sampel berwarna paling gelap atau coklat tua. Hal ini menandakan bahwa temperatur kalsinasi sangat mempengaruhi hasil sintesis ditinjau dari warna serbuk sampel. Semakin tinggi temperatur kalsinasi maka warna sampel yang dihasilkan semakin gelap.

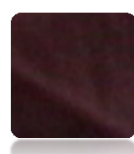

a

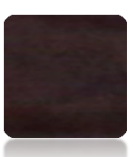

b

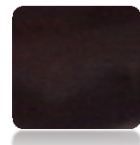

C

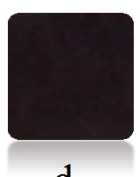

d
Gambar 5: Perubahan warna sampel $\mathrm{BaFe}_{11,4} \mathrm{Zn}_{0,6} \mathrm{O}_{19}$ berdasarkan perubahan temperatur kalsinasi. (a) $80{ }^{\circ} \mathrm{C}$; (b) 400 ${ }^{\circ} \mathrm{C}$; (c) $600{ }^{\circ} \mathrm{C}$; (d) $800{ }^{\circ} \mathrm{C}$ (Sumber: Halik, 2015)

Berdasarkan gambar 5 dapat diketahui bahwa sampel barium Mheksaferit dengan temperatur kalsinasi 80 ${ }^{\circ} \mathrm{C}$ berwarna coklat muda atau berwarna paling cerah. Sedangkan pada temperatur kalsinasi $800{ }^{\circ} \mathrm{C}$ sampel berwarna paling gelap atau coklat tua. Hal ini menandakan bahwa temperatur kalsinasi sangat mempengaruhi hasil sintesis ditinjau dari warna serbuk sampel. Semakin tinggi temperatur kalsinasi maka warna sampel yang dihasilkan semakin gelap.

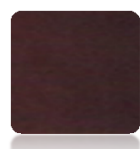

A

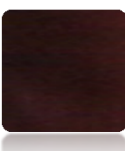

b

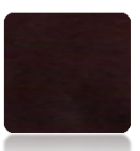

c

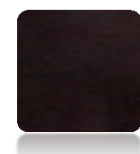

d
Gambar 6: Perubahan warna sampel $\mathrm{BaFe}_{11,1} \mathrm{Zn}_{0,9} \mathrm{O}_{19}$ berdasarkan perubahan temperatur kalsinasi. (a) $80^{\circ} \mathrm{C}$; (b) 400 ${ }^{\circ} \mathrm{C}$; (c) $600{ }^{\circ} \mathrm{C}$; (d) $800{ }^{\circ} \mathrm{C}$ (Sumber: Halik, 2015) 
Berdasarkan gambar 6 dapat diketahui bahwa sampel barium Mheksaferit pada temperatur kalsinasi $80{ }^{\circ} \mathrm{C}$ berwarna coklat muda atau berwarna paling cerah. Sedangkan pada temperatur kalsinasi $800{ }^{\circ} \mathrm{C}$ sampel berwarna paling gelap atau coklat tua. Hal ini menandakan bahwa konsentrasi dopan sangat mempengaruhi hasil sintesis ditinjau dari warna serbuk sampel. Semakin tinggi konsentarsi dopan maka warna sampel yang dihasilkan semakin gelap.

\section{KESIMPULAN}

Analisis barium M-heksaferit yang didoping dengan variasi $\mathrm{Zn} 0,0 ; 0,3 ; 0,6$ dan 0,9 dengan perubahan temperatur kalsinasi 80, 400, 600 dan $800{ }^{\circ} \mathrm{C}$ disimpulkan bahwa telah terbentuk barium M-heksaferit dalam bentuk serbuk berwarna coklat muda hingga coklat tua. Warna sampel bertambah gelap seiring dengan peningkatan konsentrasi dopan dan temperatur kalsinasi.

\section{DAFTAR PUSTAKA}

Af'idah, N,. Indahnia,. E,. \& Darminto. 2011. Sintesis Barium $M$ Heksaferit $\mathrm{BaFe}_{12} \mathrm{O}_{19}$ dengan Variasi Temperatur Kalsinasi. Makalah disajikan pada Seminar Nasional Pascasarjana XI - ITS, Surabaya, 27 Juni

Chauhan, C.C., Jotania, R.B,. Jotania, K.R. 2012. Conductivity and dielectric properties of m-type barium magnesium hexaferrite powder. International Journal of Advanced Engineering Research and Studies. I. 25-27.

Darminto,. Zainuri, M,. \& Kamariyah, E, I. 2011. Sintesis Serbuk Barium Heksaferit dengan Metode Kopresipitasi. Makalah disajikan pada Seminar Nasional Pascasarjana XI - ITS, Surabaya, 27 Juni

Fadzidah, M.I., Hashim, M., dkk. 2014. Synthesis And Characterization Of Barium-Hexaferrite Nanoparticles For Microwave Absorption. Solid State Science and Technology. 22: 12-20

Hasanah, E, Budi, A, S,. Adi, W, A,. \& Suguhartono, I. 2012. Analisis Struktur Dan Sifat Magnetik Paduan Magnet Nanokristalin Barium Heksaferit $\mathrm{BaFe}_{12} \mathrm{O}_{19}$ Dengan Metode Mechanical Milling. Makalah disajikan pada Seminar Nasional Fisika Terapan III Universitas Airlangga, Surabaya,15

September

Halik, I. 2015. Sintesis Dan Analisis Sifat Kemagnetan Dan Kelistrikan Barium M-Heksaferit Dengan Doping Zn. Tesis. Universitas Mataram

Ramli, I,. Saidah, I, N,. Findah, R, S,. \& Zainuri, M. 2012. Pengaruh Variasi Ph Pelarut Hcl Pada Sintesis Barium M-Heksaferit Dengan Doping Zn (BaFe $\left.{ }_{11,4} \mathrm{Zn}_{0,6} \mathrm{O}_{19}\right)$ Menggunakan Metode Kopresipitasi. Makalah disajikan pada Seminar Nasional Fisika Terapan III Universitas Airlangga, Surabaya, 15 September 
Saidah, I.N dan Zainuri, M. 2012.

Pengaruh Variasi $\mathrm{pH}$ Pelarut

$\mathrm{HCl}$ Pada Sintesis Barium M-

Heksaferit Dengan Doping Zn

$\left(\mathrm{BaFe}_{11,4} \mathrm{Zn}_{0,6} \mathrm{O}_{19}\right)$

Menggunakan Metode

Kopresipitasi. Jurnal Sains Dan

Seni ITS. 1: 41-46

Sholihah, F, R., \& Zainuri, M. 2012.

Pengaruh Holding Time

Kalsinasi Terhadap Sifat

Kemagnetan Barium M-

hexaferrite $\quad\left(\mathrm{BaFe}_{12-\mathrm{x}} \mathrm{Zn}_{\mathrm{x}} \mathrm{O}_{19}\right)$

Dengan Ion Doping Zn. Jurnal

Sains Dan Seni ITS. No. 1. Hal: 25-29

Sulistyo, Marhaendrajaya, I,. \& Priyono. 2012. Sintesis Dan Karakterisasi Material Magnetik Barium MHexaferrite Tersubstitusi Menggunakan Teori Sol-Gel Untuk Aplikasi Serapan Gelombang Mikro Pada Frekuensi X-Band. Jurnal Berkala Fisika. No: 2. Hal: 63 68

Susilawati, Doyan, A. 2013. Sintesis Dan Studi Pendahuluan Struktur Bahan M-Heksaferit Untuk Aplikasi Anti Radar. Prosiding Seminar Nasional Penelitian, Pembelajaran Sains Dan Implementasi Kurikulum 2013 Universitas Mataram, Mataram, 7 Desember 